NBER WORKING PAPER SERIES

\title{
A NEW SPATIAL HEDONIC EQUILIBRIUM IN THE EMERGING WORK-FROM-HOME
} ECONOMY?

\author{
Jan Brueckner \\ Matthew E. Kahn \\ Gary C. Lin \\ Working Paper 28526 \\ http://www.nber.org/papers/w28526 \\ NATIONAL BUREAU OF ECONOMIC RESEARCH \\ 1050 Massachusetts Avenue \\ Cambridge, MA 02138 \\ March 2021
}

We thank Kangoh Lee, Andrii Parkhomenko and participants in the Syracuse University Conference on Urban Economics for helpful comments. The usual disclaimer applies. The views expressed herein are those of the authors and do not necessarily reflect the views of the National Bureau of Economic Research.

NBER working papers are circulated for discussion and comment purposes. They have not been peer-reviewed or been subject to the review by the NBER Board of Directors that accompanies official NBER publications.

(C) 2021 by Jan Brueckner, Matthew E. Kahn, and Gary C. Lin. All rights reserved. Short sections of text, not to exceed two paragraphs, may be quoted without explicit permission provided that full credit, including $\left({ }^{\circ}\right.$ notice, is given to the source. 
A New Spatial Hedonic Equilibrium in the Emerging Work-from-Home Economy?

Jan Brueckner, Matthew E. Kahn, and Gary C. Lin

NBER Working Paper No. 28526

March 2021

JEL No. R14,R23

\section{ABSTRACT}

This paper studies the impacts of work-from-home (WFH) in the housing market from both intercity and intracity perspectives. Our results confirm the theoretical prediction that WFH puts downward pressure on housing prices and rents in high-productivity counties, a result of workers starting to relocate to cheaper metro areas during the pandemic without forsaking their desirable jobs. We also show that WFH tends to flatten intracity house-price gradients, weakening the price premium associated with good job access.

Jan Brueckner

Department of Economics

UCI

3151 Social Science Plaza

Irvine, CA 92697

jkbrueck@uci.edu

Matthew E. Kahn

Department of Economics

Johns Hopkins University

3100 Wyman Park Drive

Baltimore, MD 21211

and NBER

mkahn10@jhu.edu
Gary C. Lin

Department of Economics

Johns Hopkins University

3100 Wyman Park Drive

Baltimore, MD 21211

clin126@jhu.edu 


\title{
A New Spatial Hedonic Equilibrium in the Emerging Work-from-Home Economy?
}

by

\author{
Jan K. Brueckner, Matthew E. Kahn and Gary C. Lin*
}

\section{Introduction}

Cities differ in their abilities to attract workers and firms. A city such as San Francisco has an advantage in attracting workers over a city like Detroit because of its desirable attributes, including warmer winters and milder summers, less air pollution, and lower average crime levels. Dispersion in productivity also leads to differences in cities' abilities to attract workers. Some locations have a productive advantage over others because of a dense spatial concentration of jobs, creating agglomeration economies, or a favorable industry mix. Housing costs and wages adjust across space to arbitrage away these advantages. In a spatial hedonic equilibrium, where price signals and city characteristics are linked, high productivity leads to high rents and high wages, whereas high amenities are associated with high rents but lead to low wages.

In this paper, we explore how the spatial hedonic equilibrium is affected by the introduction of a work-from-home (WFH) option. Since a WFH-induced shift in the equilibrium alters the connection between where people live and what they earn and pay for housing, it is of utmost importance to understand its nature. To this end, we model WFH as an unbundling technology that allows an individual to live in one city and work in another. Breaking the link between workplace and residence allows for spatial arbitrage opportunities that were not available in the past. Workers in expensive, high-productivity places can move to cheaper, low-productivity areas while keeping their original productive jobs through remote work. The media is full of anecdotal evidence of such relocations (see Bindley, 2020), although firm statistical evidence has yet to be presented. Another possibility, less anticipated in popular discussions, is that WFH allows workers to move to high-amenity places without changing jobs. Both types of relocations have price effects, leading to a new spatial hedonic equilibrium.

\footnotetext{
${ }^{*}$ We thank Sofia Franco, Kangoh Lee, Andrii Parkhomenko, Weihua Zhao and participants in the Syracuse University Conference on Urban Economics for helpful comments. The usual disclaimer applies.
} 
To highlight these new possiblities, we develop a simple Rosen-Roback model with homogeneous workers. ${ }^{1}$ When cities differ only in productivities and WFH is introduced, workers move to cheap, low-productivity places while telecommuting to their original jobs, matching the anecdotal evidence. This residential relocation causes housing prices to fall in productive places and rise in the disadvantaged cities that receive the WFH migrants. By contrast, when cities differ only in amenities, workers move to high amenity areas under WFH while keeping their jobs in low-amenity cities. Housing prices then rise in the advantaged, highamenity places while falling in disadvantaged cities, a pattern opposite to the one in the differential-productivity case. Underlying both outcomes are two key features of the new hedonic equilibrium: wage equalization across cities, which must occur when people can work anywhere; and a disconnect between a city's population and employment levels, which are no longer equal. In the differential-amenity case, wage equalization means that housing prices do all the work in equalizing utilities (yielding stronger capitalization of amenities), whereas in the differential-productivity case, wage equalization implies that housing prices are also equalized. The resulting hedonic equilibria are novel, with features not previously seen in Rosen-Roback models.

While these patterns show the possible intercity effects of WFH, intracity effects may emerge as well. Workers who remain in their original city under WFH are likely to maintain some physical connection to the workplace, commuting to it occasionally rather than completely severing the physical link. For such workers, WFH lowers commuting costs without reducing them to zero, thereby lowering the value of access to the CBD. From the standard urban model, lower-valued access implies a reduction in the city's housing-price gradient, with prices under WFH falling more slowly than before moving away from the CBD (the job-access premium thus falls).

In the empirical section of the paper, we present evidence for both our intercity and intracity hypotheses, relying on the growth of WFH during the pandemic year of 2020. We harmonize information from several sources, using house-price and rent data from Zillow and productivity and amenity measures from Albouy (2016). Using Dingel and Neiman's (2020) industry-level

\footnotetext{
${ }^{1}$ See Rosen (1979) and Roback (1982).
} 
index of job shares in occupations that allow WFH, we create a county-level measure of WFH potential. The measure equals a weighted average of their industry indices, with the weights equal to industry employment shares in the county.

First, consistent with our intercity model, we show that the annual changes in both house prices and rents between 2019 and 2020, when the COVID-19 pandemic spurred WFH, are lower in high-productivity counties with high WFH potential. A placebo test shows that these same effects were not present in previous years, when WFH played a smaller role. Second, using monthly data, we show that high productivity and high WFH potential lead to lower levels of county house prices and rents in the months following December 2019. These results, which are based on monthly price and rent levels, reinforce the previous results using annual price changes between 2019-2020 at at finer temporal level. In contrast to these supportive results, we find no support for the model's prediction of falling prices and rents in low-amenity cities with high WFH potential. This outcome matches the pattern of popular speculation about WFH effects, which never mentions the possibility of workers moving toward better amenities under WFH.

Third, to test our intracity hypothesis of a declining house-price gradient under WFH, we combine Zillow data at the zip-code level with data from Lee and Lin (2018). We compute monthly metro-area price gradients and show that high WFH potential in the metro area's central county is associated with a flattening of the price gradient during 2020, as expected. ${ }^{2}$

We recognize the growth of WFH was not the only force affecting house-price behavior in our focal year of 2020: the effects of the pandemic-induced recession were also present. However, the house-price effects of the recession at the national level have been hardly noticeable, presumably because job losses were concentrated among lower-income workers (many of whom were unable to work from home). While prices may have been supported by lower job losses in

\footnotetext{
${ }^{2}$ After our price-gradient work was complete, we became aware of a new paper by Gupta et al. (2021) that carries out a very similar exercise. They investigate changes in intracity price and rent gradients between 2019 and 2020 and use the results to compare expectations about real-estate price growth between suburbs and the central cities, relying on changes in the price-to-rent ratio. While we present similar price-gradient results (though for a larger collection of metro areas), our main focus is on the intercity effects of WFH. Ouazad (2020) also finds evidence of increased suburbanization during 2020, but he argues that long-run population growth across cities is more strongly associated with local fundamentals, such as local productivity, than short-run shocks, including disasters and pandemics.
} 
high-WFH-potential counties, these effects should have been positive, not negative like those that we predict and find empirically. As a result, we believe that our hypothesis tests are credible despite the coincidence of the recession and the growth of WFH.

Our paper relates to a burgeoning literature on the impact of telecommuting and remote work on the US economy. Early research by Rhee (2008) and Safirova (2002) has been complemented by the recent studies of Althoff et al. (2020), Bartik et al. (2020), Brynjolfsson et al. (2020), and Dingel and Neiman (2020). Within this literature, our work is most closely related to Delventhal and Parkhomenko (2020), Delventhal, Kwon, and Parkhomenko (2020), and Larson and Zhao (2017), who build quantitative spatial models to explore the local labor market effects of telecommuting and WFH. Our simpler theoretical model and reduced-form empirical approach adds to the insights from their models. Our work is also connected to Davis, Ghent, and Gregory (2021), who estimate the elasticity of substitution between office and home work, relying on a theoretical model.

The paper proceeds as follows. Section 2 develops our theoretical predictions, while section 3 discusses the empirical model and data. Section 4 presents our results, section 5 offers perspective on the findings. Section 6 presents our conclusions.

\section{Theory}

\subsection{Intracity analysis}

The intracity effects of WFH can be analyzed in a straightforward fashion using results from the standard monocentric-city model, which predicts that the price $p$ per square foot of housing declines as the distance $x$ to the CBD increases. A key parameter in that model is the annualized round-trip commuting cost per mile, denoted $t$. Letting $x$ denote the distance to the CBD from a worker's residence, his annual commuting cost would thus equal $t x$. Under WFH, commuters make fewer trips per year to the CBD, going to the central workplace only occasionally rather than on each workday. As a result, the commuting-cost parameter $t$ falls, reflecting fewer CBD trips. As first shown by Wheaton (1974) (see also Brueckner, 1987; Duranton and Puga, 2015), the reduction in $t$ affects the spatial pattern of housing prices and population densities. As population decentralizes in the response to the decline in 
$t, p$ falls near the city center and rises in the suburbs, with the $p$ contour thus rotating in a counterclockwise fashion around some central point. The price gradient therefore falls in absolute value, reflecting the reduced benefits of CBD access. ${ }^{3}$

These outcomes occur in the long run as the city is reconfigured in response to lower commuting costs, expanding spatially and becoming less dense in the center. To derive shortrun effects when the housing stock is fixed, the slope formula $\partial p(x) / \partial x=-t / q(x)<0$ can be used, where $q(x)$ is the pre-WFH dwelling size at distance $x$. With $q(x)$ held fixed, the WFH-induced decline in $t$ makes this slope less negative, thus reducing the magnitude of the price gradient, just as in the long-run case. ${ }^{4}$

\subsection{Intercity analysis}

\subsubsection{Intercity model and equilibrium conditions}

The intercity model has two cities, denoted $s$ (San Francisco) and $d$ (Detroit), with equal fixed land areas that together accommodate a total population of $2 \bar{N} .5$ The wage in city $i$ is given by $w\left(L_{i}, \alpha_{i}\right), i=s, d$, where $L_{i}$ is employment and $\alpha_{i}$ is a shift parameter that raises worker productivity and thus the wage $\left(w_{\alpha}>0\right)$. Since this wage function is just the downwardsloping inverse demand curve for labor, $w_{L}<0$. Without WFH, a city's employment level equals its population $N_{i}$, so that the wage is given by $w\left(N_{i}, \alpha_{i}\right)$. Labor productivity is higher in city $s$ than in city $d\left(\alpha_{s} \geq \alpha_{d}\right)$, and the cities also differ in the amenities $A_{i}$ they offer, with $A_{s} \geq A_{d}$. City $s$ is thus the high-productivity, high-amenity city.

Consumer utility in city $i$ is given by the quasi-linear function $u\left(e_{i}, q_{i}, A_{i}\right)=A_{i}+e_{i}+v\left(q_{i}\right)$, where $q_{i}$ is housing (land) consumption and $e_{i}$ is non-housing consumption. ${ }^{6}$ With units of measurement for amenities and $e$ chosen appropriately, their linear utility coefficients are the

\footnotetext{
${ }^{3}$ Lock-down policies during the pandemic inhibited full enjoyment of central-city amenities, providing another reason for a drop in the benefits of central access. Another pandemic-related effect that amplifies the effects of WFH is a desire to move away from high-density areas within cities, where contagion is more of a threat.

4 This slope formula actually requires optimal adjustment of $q(x)$ and thus will not hold exactly when the lower $t$ alters $q(x)$ 's optimal value. However, as long as the post-WFH optimal $q(x)$ is close to the fixed pre-WFH value, the formula will hold approximately.

5 Rental income from the city's land flows to absentee landowners. Also, note that replacing fixed land areas with an upward-sloping housing supply function would have no effect on the ensuing results.

6 Remote work is assumed to have no effect on housing demand. The empirical study of Stanton and Tiwari (2021) recognizes, however, that the houses of remote workers may need be larger to offer adequate office space.
} 
same and equal to unity. Letting $p_{i}$ denote the unit housing price in city $i$, the consumer budget constraint is $e_{i}=w\left(N_{i}, \alpha_{i}\right)-p_{i} q_{i}$, which allows utility to be rewritten as $A_{i}+w\left(N_{i}, \alpha_{i}\right)+$ $v\left(q_{i}\right)-p_{i} q_{i}$. The last two terms represent "net housing utility" ( $v$ minus housing cost), which can be written as a function $H\left(N_{i}\right)$ of population that decreases with $N_{i}$ due to the positive effect of population on the housing price. $^{7}$ Thus,

$$
\text { utility }_{i}=A_{i}+w\left(N_{i}, \alpha_{i}\right)+H\left(N_{i}\right), \quad i=s, d
$$

Since both the wage and net housing utility decrease with $N_{i}$, utility also decreases with population.

In the equilibrium without WFH, the consumer utility expression in (1) is equalized between the two cities via migration. The non-WFH equilibrium condition is then

$$
A_{s}+w\left(N_{s}^{*}, \alpha_{s}\right)+H\left(N_{s}^{*}\right)=A_{d}+w\left(N_{d}^{*}, \alpha_{d}\right)+H\left(N_{d}^{*}\right), \quad(\text { Non-WFH })
$$

where the asterisks denote non-WFH equilibrium values. An immediate implication of this condition is $N_{s}^{*}>N_{d}^{*}$, so that city $s$ is larger than city $d$, reflecting its amenity and productivity advantages. ${ }^{8}$ With city $s$ larger, its housing price is then higher than in city $d\left(p_{s}^{*}>p_{d}^{*}\right)$.

Now suppose that WFH becomes feasible. Since an individual can now work in either city regardless of where he or she lives, equilibrium requires indifference between the two work locations, which in turn implies equalization of wages. As a result, $w\left(L_{s}, \alpha_{s}\right)=w\left(L_{d}, \alpha_{d}\right)$ must hold, where $L_{s}$ and $L_{d}$ are the employment levels in the two cities, which no longer need to be the same as the city populations. With wages the same for everyone, they drop out of the equilibrium condition (2), which is replaced by

$$
A_{s}+H\left(\tilde{N}_{s}\right)=A_{d}+H\left(\widetilde{N}_{d}\right)
$$

\footnotetext{
7 To derive the $H$ function and its properties, city land areas are normalized at unity, yielding $q_{i}=1 / N_{i}$. The housing first-order condition $\left(v^{\prime}\left(q_{i}\right)=p_{i}\right)$ then yields $H\left(N_{i}\right)=v\left(q_{i}\right)-p_{i} q_{i}=v\left(1 / N_{i}\right)-v^{\prime}\left(1 / N_{i}\right)\left(1 / N_{i}\right)$, which is decreasing in $N_{i}$. This conclusion follows because differentiation yields $H^{\prime}\left(N_{i}\right)=\left(1 / N_{i}^{3}\right) v^{\prime \prime}\left(1 / N_{i}\right)<0$, an expression proportional to minus the positive derivative of $p_{i}=v^{\prime}\left(1 / N_{i}\right)$ with respect to $N_{i}$.

${ }^{8}$ Suppose instead that the two cities had identical populations, both equal to $\bar{N}$. Then, given $A_{s}>A_{d}$ and $\alpha_{s}>\alpha_{d}$, the LHS of (2) would be larger than the RHS. Since both sides of (2) are decreasing in population, an increase in $N_{s}^{*}$ along with a corresponding decrease in $N_{d}^{*}$ makes them equal, yielding $N_{s}^{*}>N_{d}^{*}$.
} 
where the $\widetilde{N}_{s}$ and $\widetilde{N}_{d}$ are the city populations under WFH. As in the non-WFH case, city $s$ is larger than $d$ under WFH (with $A_{s}>A_{d}, \widetilde{N}_{s}$ must exceed $\widetilde{N}_{d}$ to equate the two sides of (3)). Since $\widetilde{N}_{s}>\widetilde{N}_{d}$, the housing price in city $s$ is again higher than in city $d\left(\widetilde{p}_{s}>\widetilde{p}_{d}\right)$, canceling its amenity advantage.

An implicit assumption under WFH is that a worker's productivity at a given workplace is unaffected by residential relocation to a different city. The popular discussion of WFH sometimes argues otherwise, with work that is physically remote from colleagues viewed as possibly less productive, thus commanding lower pay. ${ }^{9}$

\subsubsection{Comparing the WFH and non-WFH equilibria}

To compare the WFH and non-WFH equilibria, the first step is to rewrite (2) and (3) as

$$
\begin{aligned}
& A_{s}-A_{d}+H\left(N_{s}^{*}\right)-H\left(N_{d}^{*}\right)=w\left(N_{d}^{*}, \alpha_{d}\right)-w\left(N_{s}^{*}, \alpha_{s}\right) \\
& A_{s}-A_{d}+H\left(\widetilde{N}_{s}\right)-H\left(\widetilde{N}_{d}\right)=0
\end{aligned}
$$

From comparison of (4) and (5), the following conclusion emerges: ${ }^{10}$

$$
\tilde{N}_{s}>(<) N_{s}^{*} \quad \text { as } \quad w\left(N_{d}^{*}, \alpha_{d}\right)>(<) w\left(N_{s}^{*}, \alpha_{s}\right)
$$

In other words, WFH leads to an increase (decrease) in the population of city $s$ when its wage without WFH is lower (higher) than the non-WFH wage in city $d$.

Unfortunately, the sign of $w\left(N_{d}^{*}, \alpha_{d}\right)-w\left(N_{s}^{*}, \alpha_{s}\right)$ is ambiguous in general, making it impossible to carry out a general comparison of $\widetilde{N}_{s}$ and $N_{s}^{*}$ using (6). The source of the ambiguity is that city $s$ has dual advantages over city $d$, in both amenities and productivity. However, if city $s$ only has a single advantage, in either productivity or amenities, then definitive conclusions can be reached, as follows.

\footnotetext{
${ }^{9}$ Firms might also cut pay if remote workers face a lower cost of living. See Buhayar (2020).

10 To verify (6), note that the LHS of (4) is positive if $w\left(N_{d}^{*}, \alpha_{d}\right)>w\left(N_{s}^{*}, \alpha_{s}\right)$, and that its magnitude must be reduced to zero to satisfy the WFH condition in (5). Since $H^{\prime}<0$, this reduction requires an increase in $N_{s}$ with $N_{d}$ falling in step, yielding $\widetilde{N}_{s}>N_{s}^{*}$. Reversing this argument, $w\left(N_{d}^{*}, \alpha_{d}\right)<w\left(N_{s}^{*}, \alpha_{s}\right)$ implies $\widetilde{N}_{s}<N_{s}^{*}$.
} 
City s has higher productivity. Suppose that $A_{s}=A_{d}$ while $\alpha_{s}>\alpha_{d}$, so that the only advantage of city $s$ is higher productivity. Then (4) becomes

$$
H\left(N_{s}^{*}\right)-H\left(N_{d}^{*}\right)=w\left(N_{d}^{*}, \alpha_{d}\right)-w\left(N_{s}^{*}, \alpha_{s}\right) .
$$

Since $N_{s}^{*}>N_{d}^{*}$ holds from above, the LHS of (7) is negative given $H^{\prime}<0$, implying negativity of the RHS and thus $w\left(N_{d}^{*}, \alpha_{d}\right)<w\left(N_{s}^{*}, \alpha_{s}\right)$. From (6), this inequality in turn implies $\widetilde{N}_{s}<$ $N_{s}^{*}$, so that the population of city $s$ drops under WFH, with city d's population rising. Since $H\left(\widetilde{N}_{s}\right)=H\left(\widetilde{N}_{d}\right)$ must hold by (5) when amenities are equal, these population changes end up equating the populations of the two cities, so that $\widetilde{N}_{s}=\widetilde{N}_{d}=\bar{N}$. Equal populations in turn imply equality of housing prices, with $\widetilde{p}_{s}=\widetilde{p}_{d}$, so that prices drop in city $s$ and rise in city $d\left(\widetilde{p}_{s}<p_{s}^{*}, \widetilde{p}_{d}>p_{d}^{*}\right) .{ }^{11}$ Residents of both cities thus earn equal wages and pay equal prices, ensuring equal utilities.

WFH breaks the link between employment and population levels, with employment exceeding population in city $s$ (as outward-migrants keep their jobs) and falling short of population in city $d$. These conclusions follow because the WFH employment levels $\widetilde{L}_{s}$ and $\widetilde{L}_{d}$ lead to equal wages $\left(w\left(\widetilde{L}_{s}, \alpha_{s}\right)=w\left(\widetilde{L}_{d}, \alpha_{d}\right)\right)$, implying $\widetilde{L}_{s}>\widetilde{L}_{d}$ given $w_{N}<0, w_{\alpha}>0$ and thus $\widetilde{L}_{s}>\widetilde{N}_{s}=\bar{N}=\widetilde{N}_{d}>\widetilde{L}_{d}$.

Because of these changes, WFH leads to a new hedonic equilibrium in the economy. Prior to WFH, both the wage and the price of housing were higher in city $s$ than in city $d$, signaling the productivity difference between the cities. With WFH breaking the employment-population link, wages and prices are then equated between the cities, so that market signals no longer reveal the intercity productivity differential.

City $s$ has higher amenities. Suppose instead that $A_{s}>A_{d}$ holds while $\alpha_{s}=\alpha_{d}=\bar{\alpha}$, so that the only advantage of city $s$ is better amenities. Since $N_{s}^{*}>N_{d}^{*}$ from above and $w_{N}<0, w\left(N_{d}^{*}, \bar{\alpha}\right)>w\left(N_{s}^{*}, \bar{\alpha}\right)$ is satisfied, with (6) then implying $\widetilde{N}_{s}>N_{s}^{*}$. Therefore, the population of city $s$ expands under WFH, with residents relocating from city $d$. This

\footnotetext{
${ }^{11}$ Howard (2020) shows that migration into a city creates a beneficial construction boom. While fixed land areas in our model rule out such an effect, a more detailed framework could capture this positive effect of WFH.
} 
population shift raises the housing price in city $s$ and lowers it in city $d$, so that $\widetilde{p}_{s}>p_{s}^{*}$ and $\widetilde{p}_{d}<p_{d}^{*}$. Since city d's outward migrants keep their jobs, city d's employment under WFH exceeds its population, while employment falls short of population in city $s$. These conclusions follow because, when city $s$ has only an amenity advantage, the wage equalization condition $w\left(\widetilde{L}_{s}, \bar{\alpha}\right)=w\left(\widetilde{L}_{d}, \bar{\alpha}\right)$ implies equalization of employment, or $\widetilde{L}_{s}=\widetilde{L}_{d}=\bar{N}$. Since $\widetilde{N}_{s}>\widetilde{N}_{d}$, it follows that $\widetilde{N}_{s}>\widetilde{L}_{s}=\bar{N}=\widetilde{L}_{d}>\widetilde{N}_{d}$.

Prior to WFH, city $s$ had a higher housing price and a lower wage than city $d$, reflecting the standard outcome in the Roback (1982) model when cities differ only in amenities. Together, these differences served to offset the amenity advantage of city $s$. With wages being equalized under WFH, housing prices must do all the work in equalizing utilities, requiring a larger price differential than before. Therefore, in the new hedonic equilibrium, the role of wages disappears while that of housing prices is accentuated.

Summarizing yields

Proposition 1. When city s has both productivity and amenity advantages relative to city $d$, changes in the spatial hedonic equilibrium under WFH are ambiguous. But

(i) when city s has only a productivity advantage, population and the housing price fall (rise) in city s (in city d) under WFH. Employment exceeds (falls short of) population in city $s$ (in city $d)$.

(ii) when city s has only an amenity advantage, population and the housing price rise (fall) in city $s$ (in city d) under WFH. Employment falls short of (exceeds) population in city $s$ (in city $d)$.

Note that the population changes in part $(i)$ of the proposition match up with media anecdotes about migration out of high-productivity cities. But the effects in the amenity case (part $(i i)$ ), which are exactly the opposite of those in part $(i)$, have not been anticipated in any of the popular discussion of WFH. ${ }^{12}$

A final question concerns the wage changes experienced by the residents of the two cities under WFH. When the only advantage of city $s$ is higher productivity, the previous results yield $N_{s}^{*}>\widetilde{N}_{s}<\widetilde{L}_{s}$, which implies that $w\left(N_{s}^{*}, \alpha_{s}\right)$ could be larger or smaller than $w\left(\widetilde{L}_{s}, \alpha_{s}\right)$,

\footnotetext{
12 The existence of the opposing outcomes in Proposition 1 shows why unambiguous results cannot be derived when city $s$ has both productivity and amenity advantages.
} 
and similarly for $w\left(N_{d}^{*}, \alpha_{d}\right)$ and $w\left(\widetilde{L}_{d}, \alpha_{d}\right)$. Therefore, the original residents of city $s$ could earn more or less under WFH, with same conclusion holding for the original residents of city $d$. However, when the only advantage of city $s$ is higher amenities, $N_{s}^{*}>\bar{N}=\widetilde{L}_{s}$ implies $w\left(N_{s}^{*}, \bar{\alpha}\right)<w\left(\widetilde{L}_{s}, \bar{\alpha}\right)$, with $w\left(N_{d}^{*}, \bar{\alpha}\right)>w\left(\widetilde{L}_{d}, \bar{\alpha}\right)$ holding for city $d$. Therefore, the original residents of city $s$ (city $d$ ) earn a higher (lower) wage under WFH. Summarizing yields

\section{Proposition 2.}

(i) When city s has only a productivity advantage, its original residents could earn either a higher or lower wage under WFH, with the same conclusion holding for the original residents of city $d$.

(ii) When city s has only an amenity advantage, its original residents earn a higher wage under WFH, with the original residents of city d earning a lower wage.

Given the preceding results, the intuition underlying the effects of WFH is clear. When city $s$ has only a productivity advantage, workers can escape its high housing price by moving to city $d$ while keeping their productive city-s jobs, a movement that causes the population in city $s$ to fall short of employment. By equalizing populations, this shift eliminates the housing price differential between the cities, mirroring the equalization of wages. When city $s$ has only an amenity advantage, wage equalization under WFH means that city- $d$ workers can move to enjoy the higher amenity level without the previous wage sacrifice, keeping their city- $d$ jobs. This movement causes population in city $s$ to exceed employment and pushes up the housing price enough to exactly cancel the utility benefit from the amenity differential.

\subsubsection{WFH and blight}

Without WFH, the low housing price and small population of the disadvantaged city might lead to a blighted housing stock (Glaeser and Gyourko (2005)). By raising city d's population and housing price, WFH could partially reverse this blighted condition. ${ }^{13} \mathrm{WFH}$ could thus offer a partial cure for blight in depressed cities as people relocate there from more expensive areas without forsaking their original jobs. This conclusion is demonstrated in additional analysis that is available on request. In the modified model, housing consumption is equal to $a q$, where $a \leq 1$ is a quality factor chosen by the developer. Quality a equals 1 when housing is new but

\footnotetext{
13 City $s$ is assumed to have only a productivity advantage.
} 
declines with age, a decline that can be retarded by maintenance investment, more of which is undertaken when the housing price is high. Assuming both cities start off without WFH and with new housing in period 0 , quality in city $d$ by period 1 will have declined more than in city $s$ given $p_{d}^{*}<p_{s}^{*}$, yielding $a_{d}^{*}<a_{s}^{*}$ and the emergence of blight in city $d$ (asterisks now denote period-1, non-WFH values). However, with WFH beginning in period 2, the population shift toward city $d$ and consequent price increase will create greater incentives for maintenance investment than in city $s$. The upshot is that $\widetilde{a}_{d} / a_{d}^{*}>\widetilde{a}_{s} / a_{s}^{*}$ will hold, so that the change in housing quality between periods 1 and 2 is more favorable in city $d$ than in city $s$, indicating a lessening of blight. ${ }^{14}$

\section{Empirical Model and Data}

\subsection{Overview}

As explained in the introduction, our empirical work explores both the intracity and intercity effects of WFH. Since the intercity regressions are the most straightforward, they are presented first. To make the transition from the theoretical predictions to the empirics, recall that in the model, jobs are homogeneous and can all be done remotely. In reality, however, WFH is possible for some jobs and not for others. Therefore, the model's prediction (Proposition 1-i) that house prices fall in high-productivity cities must take into account the WFH potential of a city's jobs. Accordingly, the variable used to test this hypothesis is the interaction variable PROD $\times \mathrm{WFH}$, where $\mathrm{WFH}$ measures work-from-home potential and PROD measures productivity, both at the county level. If house prices decline when both productivity and WFH potential are high, then this interaction variable should have a negative coefficient. Similarly, the prediction (Proposition 1-ii) that house prices fall in low-amenity cities must also be conditioned on WFH potential through use of an interaction variable. Letting QOL (quality-of-life) denote the amenity measure, this interaction variable is QOL $\times \mathrm{WFH}$, and its coefficient should be positive under the hypothesis. The data used to construct these variables

\footnotetext{
${ }^{14}$ As before, the tildes denote WFH values. In the modified model, the previous equilibrium conditions are amended to incorporate housing-quality differences across cities. In addition, particular functional forms are adopted for utility and the maintenance cost function, with that function reflecting strong decreasing returns to maintenance expenditure.
} 
are described below.

To better understand this regression setup, recall that the model predicts the house-price effects of WFH when cities differ by productivity but not in amenities, and vice versa, with the effects being ambiguous when producitivity and amenities both differ. The empirical counterpart to this comparative exercise is to investigate the price effect of productivity holding amenities constant or the effect of amenities holding productivity constant. But our regressions, which include both productivity and QOL measures, achieve exactly this goal, given that the regression coefficients have a ceteris paribus interpretation. A second point to bear in mind is that, while the model predicts an absolute drop in prices in high-productivity cities with high WFH potential, the empirical goal is only to show that price changes were smaller in such cities, recognizing that prices may also have responded to additional forces.

While these regressions focus on the annual 2019-2020 house-price change as well as the change in rents, another month-based regression shows the effect of WFH potential and productivity on the levels of house prices and rents in each month of a 48-month window around December 2019. We expect a high WFH potential to depress monthly house prices and rents after December 2019 in high-productivity counties, which implies a declining pattern of the monthly WFH $\times$ PROD coefficients over this period.

To investigate the intracity effects of WFH, we again use monthly house price data, now measured at the zip-code level, and first regress prices on distance to the metro-area CBD, generating a price gradient for each MSA in each month of the same 48-month window. The estimated gradients are then used in a second-stage regression that relates their monthly mag-

nitudes to the WFH potential of the metro area's central county. We expect the monthly coefficients relating the price gradients to WFH potential to increase over the months following December 2019, indicating less-negative values. This exercise borrows data from Lee and $\operatorname{Lin}(2018)$.

\subsection{Data on WFH potential}

We measure WFH potential by combining 2018 data from County Business Patterns (the most recent data available) with the industry-level remote work index constructed by Dingel and Neiman (2020). For each NAICS3 industry, they measure the share of employment in 
occupations that can be done from home based on occupational characteristics from the US Department of Labor's Occupation Information Network $\left(\mathrm{O}^{*} \mathrm{NET}\right)$. Intuitively, an industry has a higher WFH potential if much of its employment is in occupations that require low levels of face-to-face interaction, if work involves low levels of physical effort, and if it relies less on information and communication technologies, such as e-mail. The WFH potential of county $c$ is the employment-weighted average of WFH potentials for the county's industries (denoted by $\mathrm{WFH}^{j}$ for industry $j$ ):

$$
\mathrm{WFH}_{c}=\sum_{j \in J} s_{j c} \mathrm{WFH}^{j}
$$

where $s_{j c}$ is the employment share of industry $j$ in county $c$. Table 1 shows the counties with the highest and lowest WFH potentials among the 100 largest counties. High-WFH-potential counties are concentrated in the finance and insurance hubs of the Northeast corridor as well as in the tech hubs of California. Low WFH potential counties are relatively less populous and more likely to be located in the South and the West.

\subsection{Housing data}

Our source of county-level house price and rent data is Zillow. House prices are measured using the Zillow Home Value Index, which gives selling prices for typical for houses and condominiums in a geographic area, and rents are measured by the Zillow Observed Rent Index, which captures asking rents for representative units, but whose coverage of the country is less extensive than that of the price index. These Zillow datasets are monthly time series, which we aggregate to the yearly level for the price- and rent-change regressions. In addition, the rent data, which are available at the zip-code level, are aggregated to the county level.

\subsection{Amenity and productivity data}

In addition to housing prices, critical to our analysis are measures of local amenities and productivity. We source these key variables from Albouy (2016). He builds a Rosen-Roback

model to generate hedonic estimates of QOL and productivity at the metropolitan statistical area (MSA) level. We assign these MSA-level estimates to counties based on 1999 metro area standards. An implicit assumption in our approach is that cross-county differences in amenities 
and productivity are small enough that MSA values can be assigned. ${ }^{15}$

\subsection{Other data}

We supplement the main datasets with information on the share of the population with a college degree, ${ }^{16}$ the Wharton Residential Land-Use Regulatory Index (WRLURI), measured for the county's MSA (Gyourko, Saiz and Summers, 2008), and a measure of terrain ruggedness, equal to the percent of the MSA land area with slope greater than 15 degrees (both measures are taken from Albouy, 2016). In addition, to capture the impacts of changing employment on house prices, the price-change regression includes a variable known as the Bartik "instrument," which equals the weighted average of 2019-2020 sectoral employment changes at the national level, with the weights equal to county-level sectoral job shares. ${ }^{17}$ Census-division fixed effects are also included.

The metro-area county sample includes 792 counties. However, Zillow rents are available for only 269 counties, yielding a smaller sample for the rent regressions. Summary statistics for the regression variables over the larger sample are shown in Table 2, and Figure 1 shows a point scatter of WFH potentials and productivity for major MSAs, with the values expressed as deviations from medians. ${ }^{18}$ The figure shows that WFH potential and productivity are positively correlated (at the county level, the correlation equals 0.33 ).

\subsection{Estimating equations}

Our first set of intercity regressions, which focus on the change in the annual average house price between 2019 and 2020 , are variants of the following estimating equation:

$$
\begin{aligned}
\Delta \log \mathrm{P}_{c}=\alpha_{0} & +\alpha_{1} \mathrm{PROD}_{c} \times \mathrm{WFH}_{c}+\alpha_{2} \mathrm{QOL}_{c} \times \mathrm{WFH}_{c}+\alpha_{3} \mathrm{PROD}_{c}+\alpha_{4} \mathrm{QOL}_{c} \\
& +\alpha_{5} \mathrm{WFH}_{c}+\mathrm{Z}_{c} \gamma+\epsilon_{c}
\end{aligned}
$$

\footnotetext{
15 We use the term MSA to refer to metro areas whose designation is either MSA or CMSA (the latter are the largest MSAs).

16 This share is the average county share of the college educated over the period 2014-2018 from the American Community Survey.

17 National employment changes are between the second quarters of 2019 and 2020 (the latest available quarter in the Quarterly Census of Employment and Wages). Local shares are from County Business Patterns 2018.

18 MSA WFH values are found by averaging across component counties. Note that Detroit is shown as a high-productivity city, in contrast to its status in the model of Section 2.
} 
where $c$ indexes counties, $\mathrm{P}$ denotes the house price and $\Delta \log \mathrm{P}$ is the annual 2019-2020 change, $\mathrm{Z}$ denotes the controls, and $\epsilon$ is the error term. The hypothesis that price changes are smaller in high-productivity, high-WFH-potential counties implies $\alpha_{1}<0$. Conversely, the hypothesis that prices changes are smaller in low-QOL, high-WFH-potential counties implies $\alpha_{2}>0$. In estimating (8), the standard errors are clustered at the MSA level. The same regression is also run with the change in rents as the dependent variable.

To allow the interaction coefficients in (9) to differ depending on whether the county has below- or above-median productivity or QOL, the interaction portion of (9) is rewritten as

$$
\begin{gathered}
\beta_{1} \text { low_PROD } \\
+\mathrm{PROD}_{c} \times \mathrm{WFH}_{c}+\beta_{2} \text { high_PROD } \\
+\beta_{3} \text { low_QOL }_{c} \times \mathrm{PROD}_{c} \times \mathrm{WFH}_{c}
\end{gathered}
$$

where low_PROD (high_PROD) are dummies indicate that a county has a below (above) median value of PROD, with the QOL dummies defined analogously. We present regressions based on both (9) and (10).

The monthly price-level regression, also used to test for intercity WFH effects, takes the following form:

$$
\begin{aligned}
\log \mathrm{P}_{c t}=\alpha_{c}+\sum_{t} & {\left[\delta_{t}\left(\mathrm{WFH}_{c} \times \mathrm{PROD}_{c} \times g_{t}\right)+\lambda_{t}\left(\mathrm{WFH}_{c} \times g_{t}\right)\right.} \\
& \left.+\phi_{t}\left(\mathrm{PROD}_{c} \times g_{t}\right)+\tau_{t}\left(\mathrm{QOL}_{c} \times g_{t}\right)+\left(\mathrm{Z}_{c} \times g_{t}\right) \gamma_{t}\right]+\epsilon_{c t},
\end{aligned}
$$

where $\alpha_{c}$ is a county fixed effect, $t$ denotes months, and the $g_{t}$ 's are month dummies. ${ }^{19}$ Note that the right-hand variables in (11) are constant over time but that the specification allows their price effects to vary by month. Observe also that the simpler WFH interaction structure of (9) is used, with the QOL interaction also suppressed (as explained further below). This same regression is also run using rent as the dependent variable.

\footnotetext{
19 The Bartik instrument is omitted from the controls in this regression.
} 
Turning to the intracity empirical analysis, the first stage estimates MSA-specific price gradients, one for each month (using the same 48-month window as the price-level regressions). Thus, for each metro area $m$ and month $t$, we separately estimate the following equation:

$$
\log \mathrm{P}_{m z t}=\mu_{m t}+\rho_{m t} \log \mathrm{DISTANCE}_{m z}+\mathrm{X}_{m z} \theta_{m t}+\nu_{m z t}
$$

where $m$ denotes the metro area (MSA), $z$ is the zip code, and $t$ is the month. DISTANCE denotes the distance from the zip-code centroid to the metro CBD, and $\mathrm{X}$ is a set of controls. ${ }^{20}$ Note that all coefficients in (12) vary with the metro area and month.

In the second stage, the estimated distance coefficient $\widehat{\rho}_{m t}$ from (12) is regressed on the WFH potential of the metro area's principal-city county, allowing for month-specific coefficients:

$$
\widehat{\rho}_{m t}=\sum_{t} \xi_{t}\left(W F H_{m} \times g_{t}\right)+\kappa_{m}+g_{t}+v_{m t}
$$

where $\kappa_{m}$ is a metro-area fixed effect. ${ }^{21}$ We expect the $\xi_{t}$ coefficient to rise across months, indicating flattening of the price gradient in metro areas with high-WFH-potential principalcity counties as time progresses.

\subsection{Identification issues}

Since the monthly price-level regressions in (11) use county fixed effects while the monthly gradient regressions in (13) use metro-area fixed effects, omitted variable bias is unlikely to be an issue in these regressions. In generating the annual price-difference estimating equation in (9), analogous county fixed effects in the underlying price equations are differenced out. While one could argue that unobserved factors affecting the county price changes could still

\footnotetext{
${ }^{20}$ The control variables are zip-code-level measures of $(\log )$ distance to nearest river, distance to nearest lake, distance to nearest coastline, average annual precipitation between 1971 and 2000, minimum temperature in January, maximum temperature in July, average slope, log population density, and log average household income, all drawn from Lee and Lin (2018). Their data are measured at the census tract level, and we use a crosswalk supplied by HUD to map tracts to zip codes. Note that while house size should ideally be a control in such a regression (so that it has price-per-square-foot interpretation), this variable is not available. However, inclusion of income helps offset this omission since it is generally a strong determinant of house size.

${ }^{21}$ When there are multiple principal-city counties in a metro area, we use the population-weighted average of the gradients from these counties.
} 
lead to bias, the fact that the focal variables are interaction terms appears to greatly limit the possibility of correlation with the equation's error term, thus limiting any concerns.

\section{Empirical results}

\subsection{Regressions using price and rent changes}

Table 3 shows the estimation results for the 2019-2020 price-change regressions (columns 1-4) and for the regressions using the change in the change in rents as dependent variable (columns 5-8). Column 1 of Table 3 shows that the PROD $\times \mathrm{WFH}$ coefficient is significantly negative in the price-change regression based on the specification in (9). This result confirms the prediction that 2019-2020 house-price changes were smaller in high-productivity counties with high WFH potential. However, the WFH $\times$ QOL coefficient is insignificant, disconfirming the prediction of small house-price changes in low-amenity counties with high WFH potential. Apparently, the expectation that WFH encouraged workers in such counties to move to highamenity places, depressing county house prices, is not borne out. As noted in the introduction, none of the popular commentary of WFH impacts has anticipated such an effect, possibly foreshadowing our empirical finding.

The regression in column 2 of Table 3 follows specification (10), where the interaction coefficients are allowed to differ according the magnitude of PROD or QOL. As can be seen, the coefficient of high_PROD $\times \mathrm{PROD} \times \mathrm{WFH}$ is significantly negative while that of low_PROD $\times$ $\mathrm{PROD} \times \mathrm{WFH}$ is insignificant, indicating that the $\mathrm{PROD} \times \mathrm{WFH}$ effect in column 1 is driven by WFH impacts in the highest-productivity counties. This finding provides even stronger confirmation for the predictions of the model than the results in column 1 . Mirroring the estimates in column 1, neither of the QOL interaction coefficients in column 2 is significant.

With QOL interaction effects absent, the regressions in columns 3 and 4 exclude these variables. As can be seen, the PROD $\times \mathrm{WFH}$ coefficient remains significant in column 3 , while the high_PROD interaction remains significant in column 4. The coefficient magnitudes in the corresponding regressions are also very close.

The individual level coefficients of the interacted variables show a significantly positive PROD effect on the 2019-2020 house-price change in columns 1 and 3, which disappears when 
the productivity interaction effects are split according to high and low PROD values (columns 2 and 4). While the QOL level effect is always insignificant, the WFH level effect is significantly positive in columns 2 and 4 . Note, however, that the signs of these level coefficients are not predicted by the theory. Instead, the theory says that the effect of WFH potential on price changes should be smaller in higher-productivity counties and larger in counties with higher QOL, implying negative and positive signs, respectively, for the associated interaction coefficients but with no implication for the level coefficients.

Among the control variables, the WRLURI coefficients are significantly positive in each of the columns 1-4, naturally indicating larger price changes in counties with greater landuse regulation. The college-education coefficient is always significantly negative, showing that 2019-2020 price changes were lower in highly educated counties, a result that is less transparent. Unexpectedly, the Bartik coefficient is insignificant in each of these columns, as is the terrainslope coefficient.

The rent-change regressions in columns 5-8 of Table 3 show an interaction-coefficient pattern similar to that in columns 1-4, confirming predicted rent impacts in counties with high productivity and high WFH potential. The difference is that the low_PROD $\times$ PROD $\times W F H$ coefficients in columns 6 and 8 are significantly negative along with the high_PROD $\times$ PROD $\times W F H$ coefficients, showing that the WFH effect on rents is also felt in some counties with belowmedian productivity. Among the level coefficients, all PROD coefficients are significantly positive in columns 5-8, as in columns 1-4, while the WFH levels coefficients are now uniformly negative and significant, a pattern opposite to that the earlier columns. In addition, the QOL level coefficients are significantly negative in columns 7 and 8 . The theory again provides no predictions as to the signs of these level coefficients. As for the control variables, the WRLURI coefficients become insignificant in columns 5-8, although the college education coefficients remain significantly negative in these columns. ${ }^{22}$ In addition, the Bartik coefficients become

\footnotetext{
${ }^{22}$ To further discount possible bias from omitted factors, we experimented with adding two additional controls, whose presence has little effect on the other coefficients. They are the log of total COVID-19 cases per capita in 2020 and a dummy indicating whether the metro area experienced riots or violent demonstrations in 2020. The COVID data are taken from from the New York Times (https://github.com/nytimes/covid-19-data), and the riot information is from https://acleddata.com/ special-projects/us-crisis-monitor/. The COVID coefficient is significantly negative in both the price-change and rent-change regressions, a sensible
} 
significantly positive in columns 5-8, showing that a favorable employment change has a positive effect on the 2019-2020 rent change. The terrain-slope coefficients remain insignificant.

Table 4 presents robustness checks, focusing only on the specification containing the single $\mathrm{PROD} \times \mathrm{WFH}$ interaction. Column 1 shows the results for the price-change regression when metro-area counties other than the county containing the area's prinicipal city are dropped, reducing the sample size to 378 . The interaction coefficient remains significantly negative. Column 2 shows the effect of aggregating to the MSA level, which reduces the number of observations to 236. The information loss inherent in this aggregation eliminates the significance of the PROD $\times \mathrm{WFH}$ coefficient, whose t-statistic drops to 1.5, although the sign remains negative. Column 3 provides a placebo test by replacing the 2019-2020 house-price change by the 2018-2019 price change. Since WFH took off only in 2020, we would expect to see no WFH effect on house prices between 2018 and 2019, and this expectation is confirmed by the insignificant coefficient of PROD $\times$ WFH in column 3. A regression using the 2017-2018 price change also yields an insignificant interaction coefficient. Therefore, our placebo tests are successful, showing no WFH effects where they should not be present.

Columns 4-6 of Table 4 show robustness checks when the rent change is the dependent variable, and the results are similar to those in columns 1-3. The interaction coefficient remains significantly negative when non-principal-city counties are excluded (column 4), and the coefficient becomes insignificant with aggregation to the MSA level (column 5, where the sign is now positive). The placebo test is again successful, with a regression using the 20182019 change in rents yielding an insignificant interaction coefficient. Table 4 thus shows that our results are fairly robust. ${ }^{23}$

\subsection{Monthly price-level regressions}

The results of estimating the monthly price-level and rent-level regressions in (11) are shown in Figure 2. The figures graph the monthly magnitude of the PROD $\times$ WFH interaction

outcome, and the riots coefficient is significantly positive in the price-change regressions but not in the rentchange regressions, conclusions that are less transparent.

23 Additional regressions using the change in the price-to-rent ratio (a measure of future price growth) as dependent variable show no WFH effect. Thus, prices and rents declined in step under WFH, leaving their ratio unchanged. 
coefficients relative to the coefficient for December 2019, which is normalized to zero. As shown, the regressions cover the period from 35 months prior to December 2019 through the end of 2020. The solid curve shows the estimated PROD $\times \mathrm{WFH}$ coefficients, while the dotted lines show the $95 \%$ confidence bounds. As can be seen, the magnitude of a county's PROD $\times$ WFH interaction variable has no effect on the monthly level of either housing prices or rents prior to December 2019, with the confidence bands covering the horizontal axis. But after December 2019, house prices and rents in counties with a large interaction value dropped significantly relative to their levels in this benchmark month, as predicted by the theory. This conclusion follows since the confidence bounds lie below the horizontal axis after the benchmark month. ${ }^{24}$

The results in Figure 2 reinforce the conclusions of the price- and rent-change change regressions at a more disaggregated level. The finding that monthly prices and rents fell following the benchmark month in counties with high productivity and high WFH potential matches the finding that average 2020 prices were lower than average 2019 prices in such counties.

\subsection{Monthly price-gradient regressions}

The first step in exploring the effect of WFH potential on house-price gradients is estimation of monthly price gradients at the MSA level. Zillow house-price data at the zip-code level in the sample MSAs are used rather than county-level data, so as to provide more spatial variation in prices. The resulting regressions yield a large number of price gradients across metro areas (of which there are 120) and months, and the mean value is negative (equal to -0.108), as predicted by the urban model.

Table 5 shows price-gradient regressions for the New York-Newark-Bridgeport CMSA for the months of December 2019 and 2020. We find that zip-code-level home prices in the New York metro area have a strong negative association with distance to the CBD in both periods. Furthermore, the table shows a flattening of the intracity price gradient over the year between these two months.

\footnotetext{
24 The widening of confidence band moving away from the benchmark month appears to be a consequence of the clustering of the coefficient standard errors by metro area. If robust standard errors are used instead, this widening disappears, as shown in Figure A1 in the appendix.
} 
The second-stage regression relates the estimated gradients to the WFH potential of the principal county of the metro area. The theory predicts that price gradients should have flattened (becoming less negative) in metro areas with high WFH potential, implying a positive coefficient for the WFH variable. Note that the metro area's productivity or amenities play no role in this prediction.

Following the structure of Figure 2, the results are shown in Figure 3, which graphs the magnitude of the estimated monthly WFH coefficients over the same monthly window. The coefficients are again normalized, with the December 2019 value set at zero, and confidence bounds are again shown as dotted curves. As can be seen in the figure, WFH potential has no effect on a metro area's price gradient in the months prior to December 2019. This conclusion, which is relative to the gradient in the benchmark month, follows because the confidence bands cover the horizontal axis prior to that month. After the benchmark month, however, the WFH coefficient becomes significantly larger than its benchmark value, as predicted, with the confidence bands no longer covering the horizontal axis. ${ }^{25}$ Therefore, price gradients in counties with high WFH potential flattened (becoming less negative) relative to their benchmark value in the months following December 2019. This conclusion complements our evidence on the intercity effects of WFH by showing that the value of CBD access fell in metro areas with high WFH potential, leading to a smaller price premium for central locations.

\section{A new spatial hedonic equilibrium?}

In the initial hedonic equilibrium, the high-productivity city in the theoretical model started out with high wages and high housing prices, while the disadvantaged, low-productivity city had low wages and prices. These differences served to equate utilities between the two cities. In the model, the onset of WFH initiated a movement to a new hedonic equilibrium, with housing prices falling in the high-productivity city as residents relocated to its low-price counterpart (raising prices there) while keeping their original jobs. By documenting price and rent decreases in high-productivity cities with high WFH potential, our empirical results appear to show the beginnings of such an equilibrium shift. But with WFH being a recent phenomenon,

\footnotetext{
${ }^{25}$ As seen in Figure A2 in the online appendix, when robust rather than clustered standard errors are used, the confidence band covers the horizontal axis following the benchmark month except at the very end of 2020 .
} 
it appears that the economy still has a long way to go before reaching the new predicted equilibrium, where wages within high-WFH-potential occupations are equalized across locations and the house-price premium in high-productivity cities wanes or disappears. Our empirical results suggest, though, that we may headed in this direction, with market signals of intercity productivity differences becoming muted or vanishing entirely, in stark contrast to predictions of models in the Rosen-Roback tradition. ${ }^{26}$

While the model also predicts that WFH will spur movement out of low-amenity cities toward nicer locations, our empirical results show no evidence of this kind of relocation so far. Unlike in the model, moving between cities may be difficult in the short run without a well-paid, high-productivity job, and since such jobs tend to be located in cities with favorable amenities, ${ }^{27}$ there may be little opportunity for low-to-high-amenity relocations in the short time span of our data. However, as the passage of time reduces migration frictions, we may see evidence of migration out of low-amenity areas, provided that they have high WFH potential. Such movements, which drive up housing prices in high-amenity cities, will serve to strengthen the capitalization of amenities in the housing market, as shown in the model. ${ }^{28}$

While we have not empirically explored the wage impacts of WFH (see Proposition 2), it is useful to ask what such an investigation would look like. The crucial equilibrium condition in the model is wage equalization, which occurs for all workers since jobs are homogeneous. But an empirical study would recognize that equalization would obtain only for jobs that can be done remotely. The empirical implication is that, once a WFH equilibrium has been reached, wages for jobs with high WFH potential should be independent of the place of employment and thus independent of city characteristics. Empirically, one could test this prediction by regressing the average wage on city characteristics, including amenities and productivity, along with the

\footnotetext{
${ }^{26}$ In a pre-WFH world with different size households, the high wages in high-productivity cities would be worth more to a two-earner household than to a single-earner household, drawing the former households more strongly to such places. But once WFH equalizes wages across workplaces, this location preference would disappear. Note, however, that a world with variation in the number of earners per household would require a new theoretical analysis. For a demonstration of how locational benefits can vary with the number of earners, see Gyourko and Tracy (1991, Table 4).

27 The sample correlation between PROD and QOL is 0.35 .

${ }^{28}$ Note that this stronger capitalization will hurt retirees who move to high-amenity locations at the end of their working life.
} 
WFH potential of the city's jobs as well as WFH interaction terms. The prediction would be that the effects of these characteristics on wages (acting both through level and interaction terms) would become weaker as WFH potential rises, disappearing entirely if all the city's jobs can be done remotely. Another related way of testing the wage-equalization hypothesis would be to regress an intercity occupational wage-dispersion measure on the WFH potential of the occupation, with a negative coefficient expected. In other words, occupations with high WFH potential should exhibit low wage dispersion across cities. This kind of empirical work should wait, however, for the effects of the WFH to fully play out across the economy.

\section{Conclusion}

This paper has studied the impacts of WFH in the housing market from both intercity and intracity perspectives. Our results confirm the theoretical prediction that WFH puts downward pressure on housing prices in high-productivity counties, a result of workers starting to relocate to cheaper metro areas during the pandemic without forsaking their desirable jobs. We also show that WFH tends to flatten intracity house-price gradients, weakening the price premium associated with good job access. In carrying out our tests, we do not attempt to measure population movements between cities or suburbanization trends within cities, both of which should ultimately be tied to the price effects we measure. After the WFH phenomenon has gained a stronger foothold, however, such relocation trends should be visible in population data and could be a subject for additional study. While the paper is thus being written somewhat "early in the game," our results indicate that the price effects of WFH are already apparent.

The WFH effects we identify have important economic incidence implications driven by the housing market. Our empirical results show that WFH imposes capital losses on real estate owners in high-productivity cities, while renters in such cities tend to gain. The reverse effects are predicted to occur in low-productivity cities. While these impacts are tied by the model to intercity migration, intracity effects (due to relocation within cities) will tend to hurt owners

and benefit renters in central cities, while having the reverse effects in the suburbs. Also on the intracity level, the reduction in commuting costs due to WFH may also strengthen suburbanflight responses to disamenities such as crime and high central-city taxes (Cullen and Levitt, 
1999; Mieszkowski and Mills, 1983).

Possible public-sector impacts of WFH include downward pressure on the property tax revenue of local governments (via lower housing prices) in places disfavored by WFH: central cities and high-productivity metro areas. Another public-sector effect is a possible strengthening of interjurisdictional tax competition (Wilson, 1999) as migration between jurisdictions becomes easier. This same tendency can also limit the market power of local public-sector unions, who may settle for lower pay as WFH limits their ability to extract tax revenue from increasingly footloose residents (Brueckner and Neumark, 2014; Diamond, 2017). Overall, WFH will have a host of effects that researchers should continue to track as time progresses. 
Table 1. County Rankings of Work-from-Home Potential

\begin{tabular}{cllc}
\hline \hline Ranking & County & MSA & WFH potential \\
\hline 1 & New York County, NY & New York, NY & 0.5147 \\
2 & Fairfax County, VA & Washington, DC & 0.5118 \\
3 & District of Columbia, DC & Washington, DC & 0.4942 \\
4 & San Francisco County, CA & San Francisco, CA & 0.4900 \\
5 & Santa Clara County, CA & San Francisco, CA & 0.4884 \\
6 & Suffolk County, MA & Boston, MA & 0.4682 \\
7 & Middlesex County, MA & Boston, MA & 0.4676 \\
8 & Fulton County, GA & Atlanta, GA & 0.4500 \\
9 & Hennepin County, MN & Minneapolis, MN & 0.4366 \\
10 & Collin County, TX & Dallas, TX & 0.4224 \\
$\vdots$ & $\vdots$ & $\vdots$ & $\vdots$ \\
91 & Fresno County, CA & Fresno, CA & 0.2900 \\
92 & El Paso County, TX & El Paso, TX & 0.2864 \\
93 & Snohomish County, WA & Seattle, WA & 0.2817 \\
94 & Hidalgo County, TX & McAllen, TX & 0.2788 \\
95 & Lee County, FL & Fort Myers, FL & 0.2781 \\
96 & San Bernardino County, CA & Los Angeles, CA & 0.2774 \\
97 & Kern County, CA & Bakersfield, CA & 0.2717 \\
98 & San Joaquin County, CA & Stockton, CA & 0.2687 \\
99 & Clark County, NV & Las Vegas, NV & 0.2679 \\
100 & Riverside County, CA & Los Angeles, CA & 0.2574 \\
\hline \hline
\end{tabular}

Note: This table reports county rankings in terms of WFH potential for the 100 largest counties. 
Table 2. Summary Statistics

\begin{tabular}{lccccc}
\hline \hline & $\mathrm{N}$ & Mean & St. Dev. & Min & Max \\
\hline Home price, 2020 & 792 & $244,233.80$ & $147,937.30$ & 58,736 & $1,427,988$ \\
Home price, 2019 & 792 & $233,481.90$ & $143,371.20$ & $57,392.08$ & $1,413,393$ \\
Home price, 2018 & 792 & $224,900.30$ & $143,268.80$ & $55,022.42$ & $1,396,384$ \\
Rent, 2020 & 269 & $1,631.33$ & 465.23 & 713.62 & $4,541.56$ \\
Rent, 2019 & 269 & $1,580.39$ & 477.56 & 671.00 & $4,553.26$ \\
Rent, 2018 & 269 & $1,527.53$ & 468.75 & 637.11 & $4,458.52$ \\
Work-from-Home Potential (WFH) & 792 & 0.30 & 0.06 & 0.18 & 0.69 \\
Productivity (PROD) & 792 & -0.02 & 0.11 & -0.26 & 0.29 \\
Quality of Life (QOL) & 792 & -0.01 & 0.04 & -0.10 & 0.18 \\
Pct. MSA land steeper than 15 degrees & 792 & 0.01 & 0.01 & 0.00 & 0.09 \\
Wharton Residential Land-Use Regulation Index & 792 & -0.13 & 0.73 & -1.76 & 4.31 \\
Pct. pop. with a college education & 792 & 0.29 & 0.11 & 0.09 & 0.79 \\
\hline \hline
\end{tabular}

Note: County-level home prices and rents are based on the Zillow Home Value Index (ZHVI) and Zillow Observed Rent Index (ZORI), respectively, for all homes and condos/co-ops. Because county-level ZORI is unavailable, we map zip-codelevel ZORI to counties using a HUD crosswalk. Work-from-home potential is based on authors' calculations using 2018 County Business Patterns and the Dingel and Neiman (2020) data. Metro-level productivity, quality of life, land steepness, and Wharton Residential Land-Use Regulation Index come from Albouy (2016). College population shares come from 20142018 American Community Survey. 


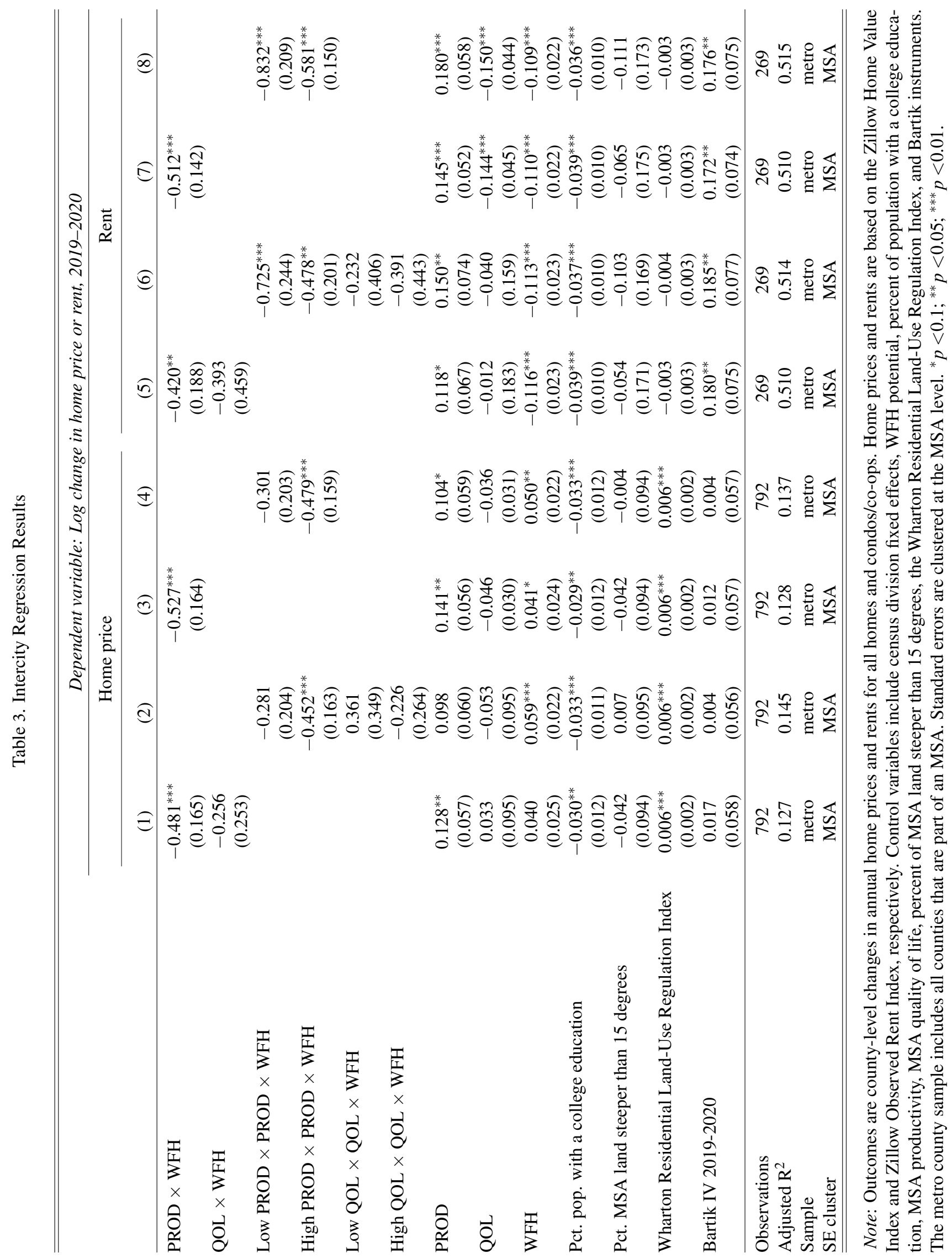




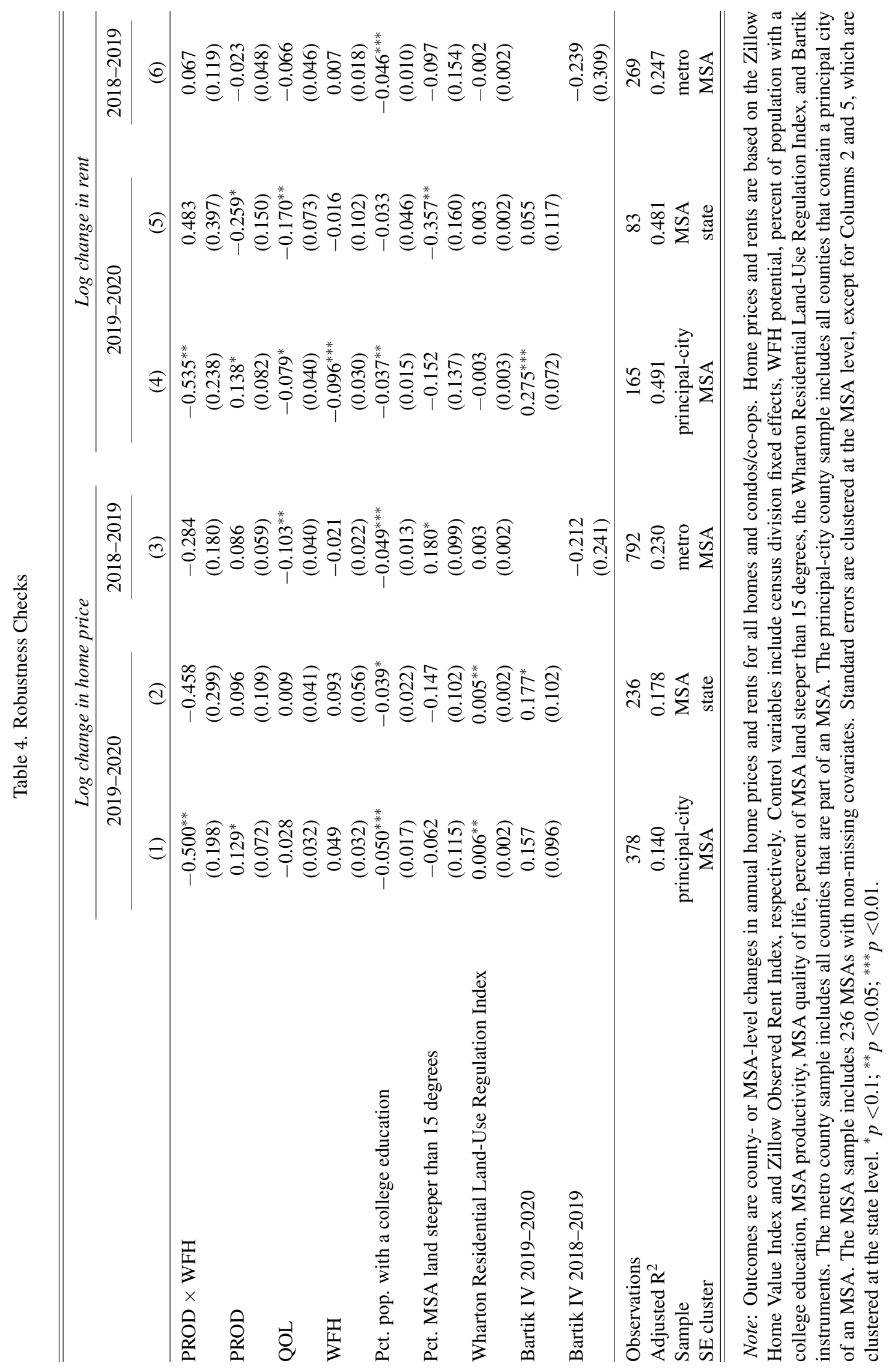


Table 5. Intracity Zip-Code Home Price Gradients, New York-Newark-Bridgeport, NY-NJ-CT-PA

\begin{tabular}{lcc}
\hline \hline & \multicolumn{2}{c}{ Dependent variable: Log home price } \\
\cline { 2 - 3 } & $12 / 2019$ & $12 / 2020$ \\
& $(1)$ & $(2)$ \\
\hline Log dist. to CBD & $-0.269^{* * *}$ & $-0.242^{* * *}$ \\
& $(0.020)$ & $(0.019)$ \\
Log dist. to nearest river & $0.050^{* * *}$ & $0.047^{* * *}$ \\
& $(0.012)$ & $(0.012)$ \\
Log dist. to nearest lake & $-0.033^{* * *}$ & $-0.033^{* * *}$ \\
& $(0.012)$ & $(0.012)$ \\
Log dist. to nearest coastline & $-0.045^{* * *}$ & $-0.052^{* * *}$ \\
& $(0.010)$ & $(0.009)$ \\
Avg. annual precipitation 1971-2000 & 0.0001 & 0.0002 \\
& $(0.0002)$ & $(0.0002)$ \\
Max temperature in July & $-0.127^{* * *}$ & $-0.123^{* * *}$ \\
& $(0.014)$ & $(0.014)$ \\
Minimum temperature in January & $0.099^{* * *}$ & $0.095^{* * *}$ \\
& $(0.012)$ & $(0.012)$ \\
Average slope & 0.002 & -0.001 \\
& $(0.003)$ & $(0.003)$ \\
Log population density & $-0.051^{* * *}$ & $-0.056^{* * *}$ \\
Log avg. hhld. income & $(0.012)$ & $(0.012)$ \\
& $0.854^{* * *}$ & $0.814^{* * *}$ \\
\hline Observations & $(0.035)$ & $(0.035)$ \\
Adjusted $\mathrm{R}^{2}$ & 842 & 842 \\
\hline \hline
\end{tabular}

Note: Home prices are based on the the zip-code-level Zillow Home Value Index for all homes and condos/coops. Zip-code covariates are based on census tract-level data from Lee and Lin (2018), which we map to zipcodes using a HUD crosswalk. 


\section{Figure 1. Relationship Between WFH Potential and Productivity, MSA}

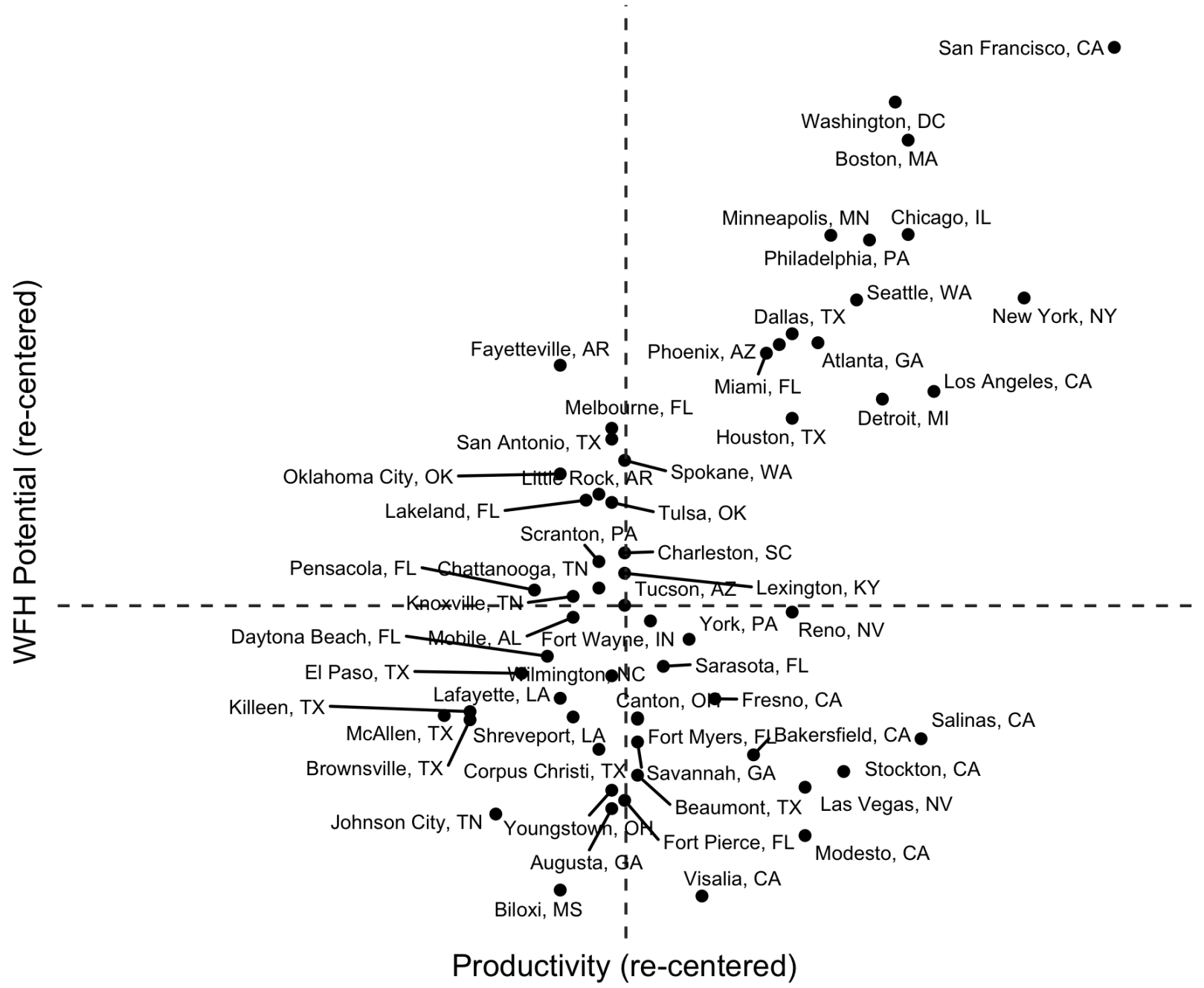

Note: Figure plots the relationship between WFH potential and local productivity for the 15 most populous MSAs (based 2019 population) in each quadrant. 


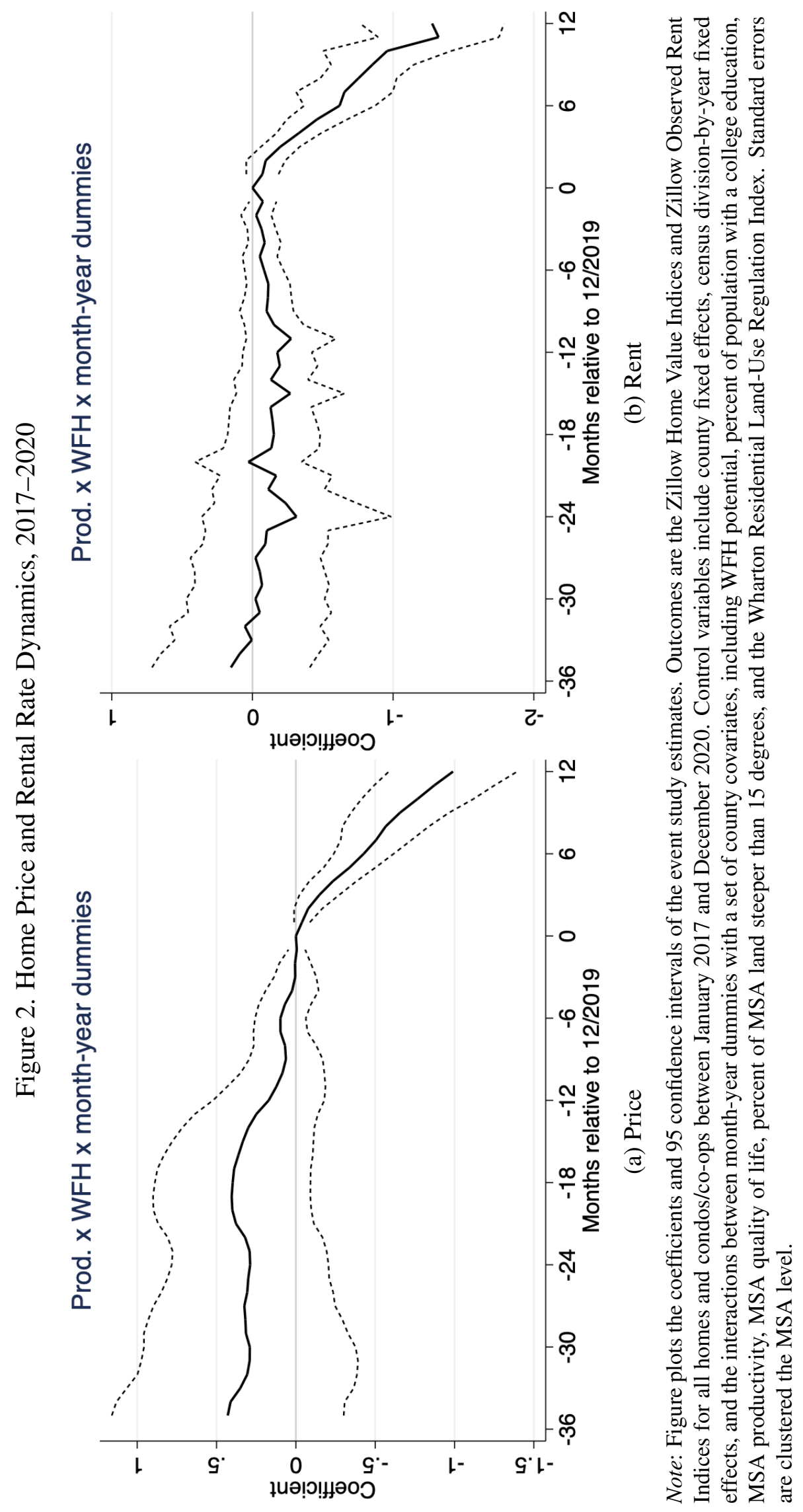


Figure 3. Intracity Home Price Gradient Dynamics, 2017-2020

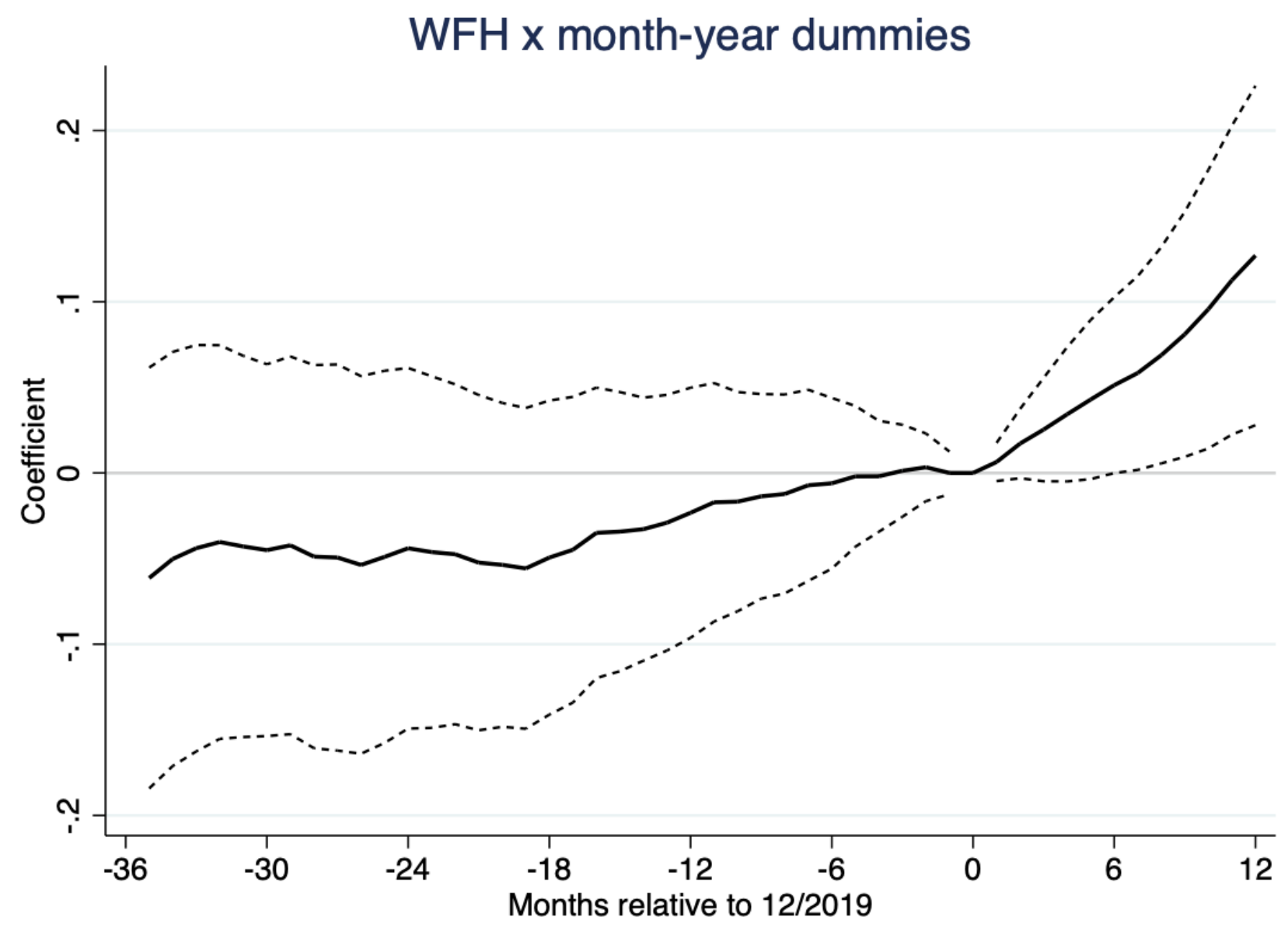

Note: Figure plots the coefficients and 95 confidence intervals of the event study estimates. Outcomes are intracity home price gradients based on authors' calculations. In the first stage, we estimate the intracity home price gradient of each MSA with at least 30 zip-codes by separately regressing log zip-code Zillow Home Value Index on log distance to the central business district, a set of exogenous amenities (log distances to nearest lake, river, and coastline; the average annual precipitation 1971-2000, January minimum temperature, and July maximum temperature), average slope, and a set of proxies for endogenous amenities (log population density and log average household income). In the second stage, we estimate an event study equation by regressing the estimated intracity home price gradients on the interactions of month-year dummies and principal-city counties' WFH potential, controlling for MSA fixed effects and month-year fixed effects. Standard errors are clustered the MSA level. 


\section{References}

Albouy, David. 2016. "What Are Cities Worth? Land Rents, Local Productivity, and the Total Value of Amenities." Review of Economics and Statistics 98(3): 477-487.

Althoff, Lukas, Fabian Eckert, Sharat Ganapani and Conor Walsh. 2020. "The City Paradox: Skilled Services and Remote Work," CESifo working paper 8734.

Bartik, Alexander W., Zoe B. Cullen, Edward L. Glaeser, Michael Luca, And Christopher T. Stanton. 2020. "What Jobs are Being Done at Home During the Covid19 Crisis? Evidence from Firm-Level Surveys." National Bureau of Economic Research working paper 27422.

Bindley, Katherine. 2020. "Tech Workers Take to the Mountains, Bringing Silicon Valley With Them." Wall Street Journal, November 1.

Bloom, Nicholas, Steven J. Davis, and Yulia Zhestkova. 2020. "COVID-19 Shifted Patent Applications Toward Technologies that Support Working from Home." SSRN Scholarly Paper 3695191.

Brueckner, JAn K. 1987. "The Structure of Urban equilibria: A Unified Treatment of the Muth-Mills Model," in: Edwin S. Mills, ed., Handbook of Regional and Urban Economics (North-Holland, Amsterdam), Vol. 2, 821-845.

Brueckner, Jan K., And David Neumark. 2014. "Beaches, Sunshine, and Public Sector Pay: Theory and Evidence on Amenities and Rent Extraction by Government Workers." American Economic Journal: Economic Policy 6(2): 198-230.

Brynjolfsson, Erik, John J. Horton, Adam Ozimek, Daniel Rock, Garima Sharma, And Hong-Yi TuYe. 2020. "COVID-19 and Remote Work: An Early Look at US Data." National Bureau of Economic Research working paper 27344.

Buhayar, Noah. 2020. "The Work-From-Home Boom Is Here to Stay. Get Ready for Pay Cuts." Bloomberg Businessweek, December 18.

Cullen, Julie B., And Steven D. LevitT. 1999. "Crime, Urban Flight, and the Consequences For Cities," Review of Economics and Statistics 81(2): 159-169.

Davis, Morris A., Andra C. Ghent and Jesse Gregory. 2021. "The Work-at-Home Technology Boom and its Consequences," National Bureau of Economic Research working paper 28461. 
Delventhal, Matthew, And Andrit Parkhomenko. 2020. "Spatial Implications of Telecommuting." Unpublished paper.

Delventhal, Matthew, Eunjee Kwon, And Andrit Parkhomenko. 2020. "How Do Cities Change When We Work from Home." Unpublished paper.

Diamond, Rebecca. 2017. "Housing Supply Elasticity and Rent Extraction by State and Local Governments." American Economic Journal: Economic Policy 9(1): 74-111.

Dingel, Jonathan I., And Brent Neiman. 2020. 'How Many Jobs Can Be Done at Home?" Journal of Public Economics 189: article 104235.

Duranton, Gilles, and Diego Puga. 2015. "Urban Land Use." In: J. Vernon Henderson, William C. Strange and Gilles Duranton, eds., Handbook of Regional and Urban Economics (North-Holland, Amsterdam), Vol. 5, 467-560.

Glaeser Edward L., and Joseph Gyourko. 2005. "Urban Decline and Durable Housing." Journal of Political Economy 113(2): 345-375.

Gupta, Arpit, Vrinda Mittal, Jonas Peters and Stijn Van Nieuwerburgh. 2021. "Flattening the Curve: Pandemic Induced Revaluation of Urban Real Estate." Unpublished paper.

Gyourko, Joseph, And Joseph Tracy. 1991. "The Structure of Local Public Finance and the Quality of Life." Journal of Political Economy 99(4): 774-806.

Gyourko, Joseph, Albert Saiz, And Anita Summers. 2008. "A New Measure of the Local Regulatory Environment for Housing Markets: The Wharton Residential Land Use Regulatory Index." Urban Studies 45(3): 693-729.

Howard, Greg. 2020. "The Migration Accelerator: Labor Mobility, Housing and Demand." American Economic Journal: Macroeconomics 12(4): 147-179.

Larson, William, and Zhao, Weihua. 2017. "Telework: Urban Form, Energy Consumption, and Greenhouse Gas Implications." Economic Inquiry 55(2): 714-735

Lee, Sanghoon, And Jeffrey Lin. 2018. "Natural Amenities, Neighbourhood Dynamics, and Persistence in the Spatial Distribution of Income." Review of Economic Studies 85(1): 663-694.

Ouazad, Amine. 2020. "Resilient Urban Housing Markets: Shocks vs. Fundamentals." arXiv.org preprint 2010.00413.

Mieszkowski, Peter, And Edwin S. Mills. 1993. "The Causes of Metropolitan Subur- 
banization." Journal of Economic Perspectives 7(3): 135-47.

Rhee, Hyok-Joo. 2008. "Home-based Telecommuting and Commuting Behavior." Journal of Urban Economics 63(1): 198216.

Roback, Jennifer. 1982. "Wages, Rents, and the Quality of Life." Journal of Political Economy 90: 1257-1278.

Rosen, Sherwin. 1979. "Wages-based Indexes of Urban Quality of Life." In: Peter Mieszkowski and Mahlon Straszheim, eds., Current Issues in Urban Economics (Baltimore, Johns Hopkins Univ. Press).

Safirova, Elena. 2002. "Telecommuting, Traffic Congestion, and Agglomeration: A General Equilibrium Model." Journal of Urban Economics 52(1): 26-52.

Stanton, Christopher T., and Pratyush Tiwari. 2021. "Housing Consumption and the Cost of Remote Work." National Bureau of Economic Research working paper 28483.

Wheaton, William C. 1974. "A Comparative Static Analysis of Urban Spatial Structure." Journal of Economic Theory 9(2): 223-237.

Wilson, John D., 1999. "Theories of Tax Competition." National Tax Journal 52(2): 269304. 


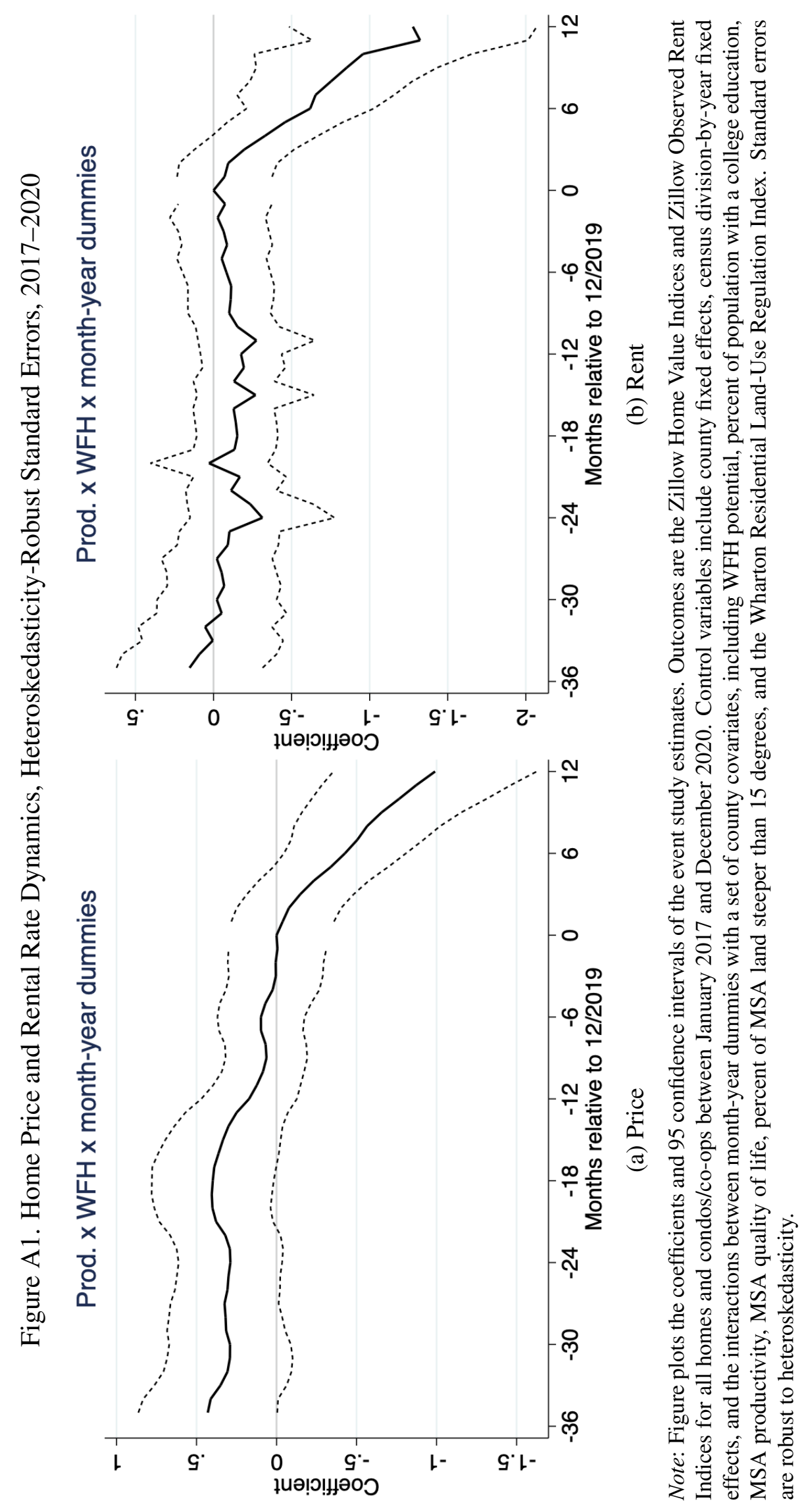


Figure A2. Intracity Home Price Gradients, Heteroskedasticity-Robust Standard Errors, 2017-2020

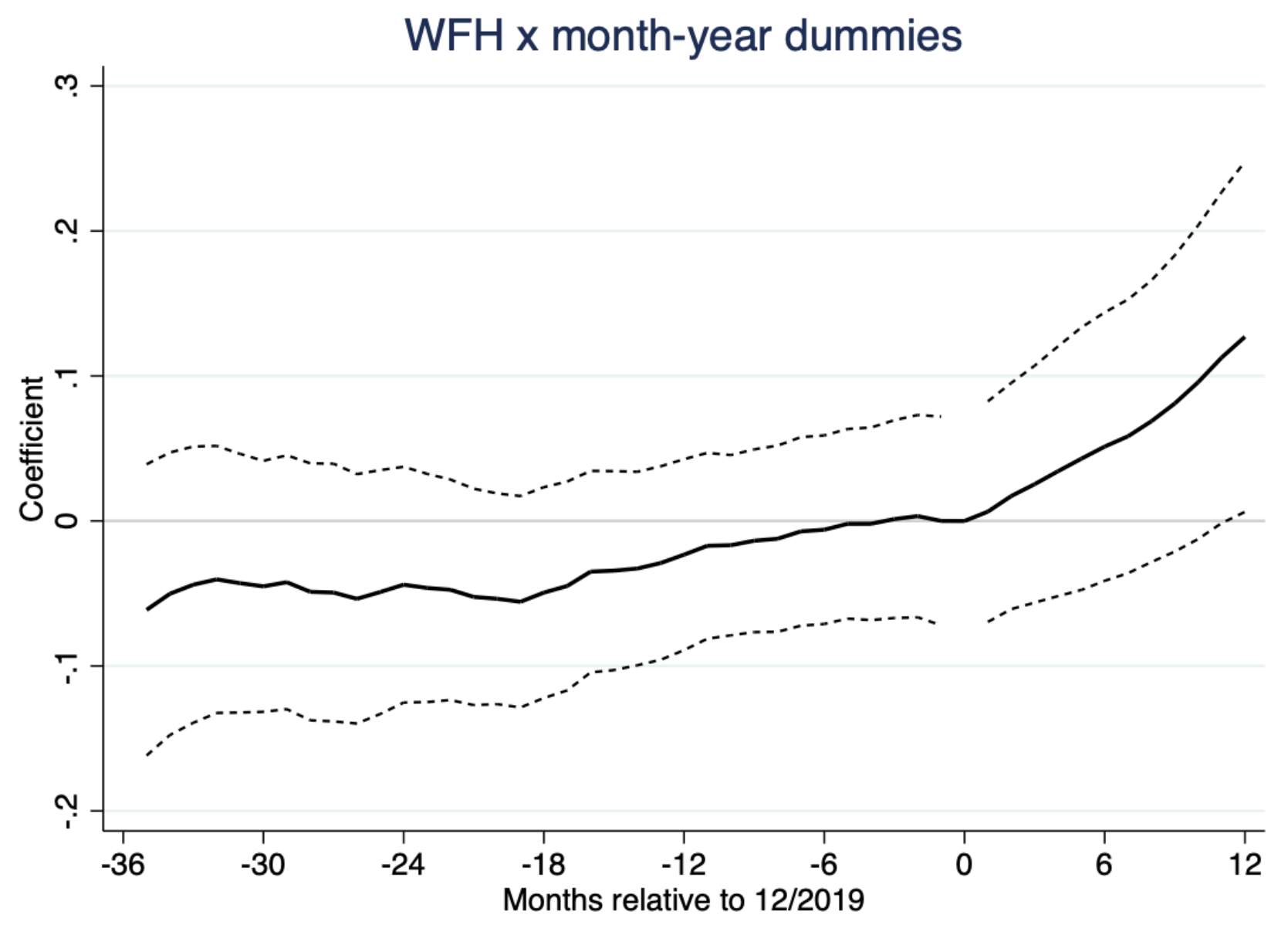

Note: Figure plots the coefficients and 95 confidence intervals of the event study estimates. Outcomes are intracity home price gradients based authors' calculations. In the first stage, we estimate the intracity home price gradient of each MSA with at least 30 zip-codes by separately regressing log zip-code-level Zillow Home Value Index on log distance to the central business district, a set of exogenous amenities (log distances to nearest lake, river, and coastline; the average annual precipitation 1971-2000, January minimum temperature, and July maximum temperature), average slope, and a set of proxies for endogenous amenities (log population density and log average household income). In the second stage, we estimate an event study equation by regressing the estimated intracity home price gradients on the interactions of month-year dummies and principal-city counties' WFH potential, controlling for MSA fixed effects and month-year fixed effects. Standard errors are robust to heteroskedasticity. 